\title{
FICCIÓN Y EROTISMO. LA REUBICACIÓN DEL CUERPO EN LA FICCIÓN ESPAÑOLA CONTEMPORÁNEA
}

\section{Cuerpo y novela}

Es apropiado que un ensayo sobre el erotismo empiece con una consideración en torno al cuerpo. El cuerpo entendido no como un recipiente o receptor pasivo de un contenido externo (una idea, un alma) y, por tanto, un elemento secundario de la significación, sino como un generador de significado, un signo primordial de la discursividad (Foucault, 20). Poner, además, el cuerpo en relación con la narración ficcional implica que ese concepto del cuerpo está realizado concretamente dentro de una estructura dinámica, en progresión articulada y coherente y en interconexión con otros cuerpos. Ubicar el cuerpo dentro de un contexto diferencial-el español-conlleva, además, el que ese cuerpo actúa y se visualiza de una manera específica, determinada por unos parámetros culturales. Tres son, por consiguiente, los presupuestos preliminares de mi ensayo. Es una reflexión en torno a los modos de significación del cuerpo y sus ramificaciones (deseo, sexualidad, afectividad); esa reflexión se hace dentro de la ficción; y con el referente específico de la ficción (novela y cine) espanola contemporánea.a.

\section{La existencia conflictiva del cuerpo}

Lo corporal ha tenido una presencia altamente contestada dentro de la cultura española. Otros modelos culturales han cuestionado también el cuerpo, desde el discurso calvinista centroeuropeo a la Inglaterra victoriana. No obstante, en la cultura española moderna, lo corporal se ha manifestado con reservas, en un enfrentamiento abierto o indirecto con una superestructura ideológica-religiosa, política-que lo obstaculiza y veta. El cuerpo y sus manifestaciones concomitantes-el deseo, la sensualidad y la sexualidad-no han podido manifestarse con independencia y han visto su movimiento condicionado por la superestructura que los restringe. Esta situación se ha desarrollado de manera explícita con el espiritualismo del Barroco (desde Santa Teresa a Zurbarán y Ribera) hasta la Kulturkampf del siglo XIX en donde, bajo la inspiración del papa integrista Pío IX, la negación de lo físico y temporal se convierte en el caballo de batalla de una ideología que se siente amenazada. Dona Luz, de Juan Valera, y La regenta, de Clarín, son algunas manifestaciones del modo en que el cuerpo se transforma en la metáfora por excelencia, la clave definitoria de una posición intelectual. Doña Luz lleva a la práctica en sí misma la primacía de lo no-físico, la imperativa supresión subliminal del cuerpo para alcanzar un estado personal superior. Ana Ozores revela la imposibilidad de negar los impulsos del cuerpo que, en su caso, emergen de manera caótica y desestabilizadora precisamente porque son sometidos a una prohibición contranatural.

La virulenta lucha ideológica de la segunda mitad del siglo diecinueve se continúa por otros medios en el siglo posterior y alcanza sus últimas manifestaciones en la actu- 
alidad cuando se clausura el ciclo de esa conflictividad. Se puede afirmar, por tanto, que el largo proceso de afirmación del cuerpo no concluye hasta la fase actual de aceptación y normalización de lo corporal. El cuerpo-el deseo, eros-no sólo alcanzan legitimidad sino que se hacen habituales, incluso rutinarios y, con esa cotidianeidad, afirman su presencia incontrovertible. En su proceso de ruptura antinormativa, la novela posmoderna en particular ha desideologizado el cuerpo, le ha desprovisto de la militancia ideológica que ha poseído durante largo tiempo (Gibson, 78). Esa desideologización concluye el proceso de combatividad con relación al cuerpo que constituye unos de los rasgos de la cultura española.

Concentrémonos en la novela de las últimas décadas del siglo, con una primera referencia al modo novelístico que supone la primera ruptura con el modelo prevaleciente en la posguerra: la novela social de los años cincuenta que irrumpe en el medio cultural español con el propósito específico de renovar el limitado repertorio intelectual nacional ocasionado por la situación excepcional del país. Esa novela se visualiza a sí misma como un modelo de oposición al status quo y propone una visión social, política y cultural alternativa que finalmente debe sustituir a la realidad prevaleciente. El texto literario se convierte para ella en un vehículo para la obtención de una sociedad diferente. No obstante, más allá de ese propósito fundacional, esa novela no materializa sus objetivos. En sus aspectos técnicos, produce una novela convencional. En su dimensión ideológica, es conservadora a pesar de proclamarse rebelde e incluso revolucionaria. Un ejemplo se halla en su visión del cuerpo que, en lugar de innovar, reproduce modelos previos.

En la novela social, el cuerpo está ausente, no tanto porque esté intencionalmente negado sino porque queda abrumado por un conjunto de factores y causas externas que impiden su irrupción libre: los motivos del cuerpo se juzgan secundarios a los de otras causas que se juzgan como más urgentes. En la novela social, desde Central eléctrica a La piqueta, hay un intento de proyecto de una mayor libertad individual y colectiva pero ese proyecto se formula de un modo abstracto que impide una consideración específica. El espacio del cuerpo es dispensable frente al imperativo de transformar la estructura social y política de una sociedad inamovible.

El paralelo con Unamuno es especialmente sugestivo porque el movimiento de la novela social se percibe como claramente contrario a ese autor precisamente por considerar que su obra evade los datos objetivos de la realidad concreta. Para Unamuno, el cuerpo es una distracción y la sensualidad es una tentación que la mente debe eludir para no entrar en un territorio que la aleja de lo que debe ser su verdadera preocupación: la búsqueda de una estrategia intelectual para alcanzar la trascendencia última del yo. El origen de la negación del cuerpo es en él existencial y se vincula con la corriente espiritual y religiosa que, desde el siglo XVII, ha juzgado al cuerpo como un componente separable del pensamiento.

La novela social llega a parecida conclusión aunque por razones distintas y desde una motivación también diferente. La negación del cuerpo se produce ahora de manera paradójica. El pensamiento liberal ha hecho de la elaboración de un discurso en torno al cuerpo, el erotismo y la sexualidad un argumento de su enfrentamiento al status quo. No obstante, en esa novela lo físico aparece elidido más allá de la intencionalidad de la con- 
ciencia textual. El cuerpo no se menciona a pesar de que la conciencia textual lo considera como un tema legítimo e incluso necesario del repertorio novelístico. Hay algunos intentos que se alejan de esa elisión del cuerpo. Son, no obstante, amagos más que propuestas completas. En la novela, un caso es Fin de fiesta, de Juan Goytisolo, cuyo subtítulo, "Tentativas de interpretación de una historia amorosa," es revelador de la incipiencia de ese intento que no llega a profundizar en las dimensiones físicas y eróticas de las relaciones humanas. En el cine, Historia de un ciclista, de J.A. Bardem, cuyo planteamiento de las relaciones extramatrimoniales se presenta como una metáfora de la falsedad moral del momento sin llegar a concentrarse en las relaciones eróticas que, de nuevo, aparecen suprimidas por completo (Higginbotham, 34). En ambos casos, el cuerpo está presentado tangencialmente y los elementos eróticos, si llegan a ser mencionados, aparecen más por alusión que por referencia directa.

\section{El cuerpo como centro}

Esta situación de evasión corporal y erótica se mantiene con variaciones hasta el final de la Dictadura. En realidad, la irrupción del cuerpo es uno de los factores determinantes de la estética que emerge bajo la nueva situación. Este hecho obedece a varias causas. En primer lugar, por su carácter previamente negado, el cuerpo asume una función de oposición frentre al statu quo. Afirmar el cuerpo, mostrar la gama de posibilidades del deseo, exponer abiertamente los aspectos de la sensualidad y el erotismo son modos inequívocos de oponerse a la coacción y la opresión pasadas. La aserción de los derechos del oprimido frente a fuerzas superiores es el acto de rebelión de la novela social. Esa novela no llega concebir el cuerpo como un vehículo de combate ideológico porque considera que la concentración en el erotismo es un alejamiento de objetivos más amplios. Para la nueva ficción, por el contrario, el cuerpo se ofrece como un instrumento idóneo para delinear una separación ideológica con relación a las fuerzas que lo negaron en el pasado. El cuerpo sirve así como una metáfora general de la nueva situación epistémica.

El minimalismo, que, como han argüido Lipovetsky y Vattimo, compone el paradigma ético de nuestro momento, no impide que emerjan también dentro de él elementos maximalistas de afirmación (Kellner, 152). La extensión del cuerpo a categoría predominante y en algunos casos incluso absoluta corrobora y magnifica la negación de los sistemas ontológicos e ideológicos que caracteriza la estética finisecular. Afirmar lo corporal es el positivismo de nuestro momento, el acto objetivamente tangible de la exposición y análisis de los sentidos. Lejos del materialismo experimental de Comte, Claude Bernard, Zola y Blasco Ibáñez y de sus ambiciones absolutizantes, pero positivismo en cuanto que se centra en el hic et nunc de lo físico para contrarrestar el peso ontológico de la tradición hispana en la que negación de lo material y concreto ha sido determinante. Consideraré los rasgos específicos de esta nueva situación a partir de algunos textos emblemáticos.

La primera característica del nuevo erotismo es su reconfiguración de la división genérica convencional. La novela realista y modernista previa a la guerra civil así como la novela social están todavía estructuradas en torno a la división estricta en género sexual 
(masculino/femenino) con un predominio claro de la perspectiva masculina. Los textos decisivos de Baroja, Pérez de Ayala, Cela, Ferres, etc. están concebidos desde una mirada masculina en la que la perspectiva femenina es limitada y existe sólo de manera subordinada y tangencial. La mujer aparece como un partner secundario que da apoyo a la acción del hombre. Es el destinatario de la mirada, no mira ella misma y en esa mirada halla su identificación y definición.

La ficción reciente replantea de manera determinante estos presupuestos de identidad sexual y personal. Esta transformación ocurre a través de un proceso de reconstitución de las relaciones sexuales. Hay una reversión del agente erótico y de quién lo narra. Quien realiza lo narrado y quien lo narra son una mujer o una voz narradora que actúa la sexualidad desde una perspectiva femenina. De receptor la mujer pasa a ser agente y de ser percibida y narrada la mujer ve y narra de manera central. La consecuencia más inmediata de esta reversión es el que las relaciones eróticas y sexuales no cambian tanto de contenido-el intercambio erótico entre dos sujetos-como de orientación y ordenación jerárquica de lo presentado. El repertorio de posibilidades eróticas y afectivas no sufre un cambio extraordinario. Lo que cambia es el foco y evaluación de ese repertorio. Las emociones, el placer, las pulsiones emotivas son vistas de manera diferente y esa visión las hace cambiar en su naturaleza. Tres textos ficcionales escritos y uno cinematográfico servirán de apoyo para esta caracterización.n.

Las edades de Lulú, de Almudena Grandes, es una novela paradigmática de la reversión erótica. La novela puede leerse como un Bildungsroman que conduce a la protagonista desde la inseguridad de la primera adolescencia a un reconocimiento de una primera madurez al final de un proceso de transformación personal. En ese proceso, Lulú experimenta muchas vicisitudes e incluso fracasos y el desenlace de ese proceso se caracteriza por su ambivalencia e incertidumbre. Lo más significativo en este caso no es tanto el contenido del proceso como el que el originador del proceso sea una mujer que asume ese protagonismo de manera consciente. Según sus propias palabras, su conquista es haber obtenido la capacidad de decisión en las relaciones humanas íntimas. Esa capacidad de decisión no le proporciona la dicha ansiada pero le otorga la libertad personal y la posibilidad de delimitar y definir esa libertad con sus propias palabras: "Seguridad. El derecho a decir cómo, cuándo, dónde, cuánto y con quién. Estar al otro lado de la calle, en la acera de los fuertes. El espejismo de mi madurez" (Las edades, 197). La fortaleza y confianza frente a la inseguridad y vacilación previas son los rasgos determinantes.

No obstante, en esta novela, como antes ocurre en las novelas de Esther Tusquets, el cambio de orientación genérico-sexual en la perspectiva narrativa no implica necesariamente una transformación cualitativamente superior en las relaciones humanas. En el caso de Esther Tusquets, sus personajes femeninos heterosexuales acaban revirtiendo en modelos de dominación masculina dentro de los curales esos personajes se someten al mismo proceso de sojuzgamiento del que se habían evadido previamente. Sus personajes homosexuales reinciden en relaciones de poder incluso más pronunciadas que las heterosexuales que esos personajes rechazan y perciben como contramodelo. La narradora de El mismo mar de todos los veranos y Elena, la protagonista de Para no volver son ejemplos de este retorno al estado previo al intento de autonomía y libertad individual. De 
modo paralelo, en Las edades de Lulú, la libertad sexual absoluta de Lulú concluye no en una exaltación de la independencia y la aserción individual sino en el retorno de Lulú al modelo de sujeción a Pablo del que había querido separarse. El regreso al "hogar" arcádico es para ella una irónica forma de redención: "Rodé sobre las sábanas, hasta instalarme en su lado, y me concentré en rastrear su olor, no resultó fácil, no andaba muy fina de olfato aquella mañana, pero al final encontré una nota reveladora encima de la almohada ...y me quedé inmóvil, encogida, sonriendo, colgada de aquel olor, dejando pasar el tiempo" (Las edades, 260). Tras su proceso de experimentación con la libertad y el riesgo, Lulú concluye su experiencia con una reactualizacion del statu quo ante. El proceso no ha sido, no obstante, infructuoso. Ha adquirido una conciencia de la que carecía antes de haber iniciado su camino diferencial. En su caso, la experimentación erótica personal le ha servido para aumentar su lucidez con relación a su condición. Lulú anhelaba una demarcación nítida de su vida personal que decidiera claramente su identidad. En lugar de ello, se ha instalado definitivamente en la ambivalencia, la indefinición, propias de la devaluación axiológica que caracteriza la situación epistémica actual.

El texto de otra novelista, Beatriz y los cuerpos celestes, de Lucía Etxebarría, somete el modelo de la novela de educación personal a un proceso de ironización en el que la búsqueda de absolutos no alcanza corroboración sino que acaba disolviéndose en la incertidumbre de donde el personaje había partido inicialmente y de la que había querido alejarse de manera definitiva. Beatriz parte del escepticismo con respecto a las relaciones humanas afectivas; trata de superarlo en intentos diversos y finalmente reincide en el escepticismo y la reducción última de sus expectativas. Su yo recibe un incremento de saber al término de su turbulenta trayectoria, pero es un saber que no se caracteriza por una exultación epifánica, al modo en que la protagonista de To the Ligthhouse de Virginia Woolf lo experimenta : "I have had my vision" concluye la narradora de esa novela emblemática (To the Ligthhouse, 310). Esa resolución exaltante es propia de la estética circular del modernismo europeo (Modernism, 397). Ahora nos hallamos en una situación distinta de devaluación de los procesos que se clausuran de manera final y completa. Por ello, el nuevo saber de Beatriz se manifiesta cuando ella se instala en la reducción de las esperanzas humanas amorosas. Beatriz advierte que su redención personal consiste en la aceptación del compromiso afectivo, la conciencia de las limitaciones del yo y del otro en el intercambio amoroso: "En el mundo hay millones de parejas que han ido forjando su relación a base de mucha voluntad y de pequeñas renuncias compartidas ... Es el ansia de perfección la que asesina los afectos ... Yo ya no aspiro a grandes fuegos... Ahora sólo espero renacer de mis cenizas ..., ese rescoldo que suponen los gestos familiares, el calor conocido de los labios y las serenidad tantos días encontrada en unos ojos en los que no brillan ni la ansiedad ni el deseo excesivos... La paz, a fin de cuentas. O el amor" (Beatriz, 265).

Beatriz inicia su periplo individual a la búsqueda de un absoluto personal, la realización con el otro/a de un proyecto de vida compartida. Sus experiencias en Edimburgo y Madrid son extremas porque, en su opción radical, señalan su separación de la convención y la rutina. Es esa misma convención y rutina la que significa su retorno a "los gestos familiares." No obstante, la persona que hace esta renuncia no es la misma que 
emprende el camino al principio de la narración. Entre esos dos yos hay una diferencia notable. En la renuncia al absoluto, Beatriz halla una nueva identidad que no es la que había proyectado pero que se ajusta más adecuadamente a su realidad presente. La reducción de su horizonte de expectativas señala un nuevo conocimiento y ese conocimiento supone una compensación por la empresa afectiva y erótica iniciada con tanta dedicación y ahínco. En su caso, el fracaso del proyecto afectivo conlleva un modo de realización personal superior.

En la ficción cinematográfica, Amantes, deVicente Aranda, señala la realización de un proyecto afectivo femenino a partir de la ruptura de convenciones sociales rígidas. De nuevo, la narración otorga a una mujer la agencia principal de lo presentado. Es, además, una mujer que, dentro del ambiente asfixiante de la primera época del franquismo, está dispuesta a romper una normativa restrictiva, en particular, la de las relaciones sexuales. Su motivación no es impecablemente moral y desinteresada, como tampoco lo es la de Lulú, Beatriz y los personajes deTusquets. En esos casos, el deseo de dominación, la inseguridad personal y la angustia son los impulsos centrales de la aserción de las figuras femeninas más que la conciencia de una situación personal lastrada por la condición sexual. En el caso de la protagonista de Amantes su impulso obedece a causas más mezquinas y la lleva a conculcar cualquier escrúpulo moral. Por esa razón, para ella, el juego erótico se transforma progresivamente en un modo de obtener sus objetivos personales a través de la mediatización de su amante. Ella asume la posición directiva en su relación con un hombre mucho más joven e inexperimentado que ella $\mathrm{y}$, a través de la obsesión física, lo lleva al rechazo del compromiso contraído con su novia y últimamente a su asesinato. La muerte de su novia significa la afirmación del deseo de poder como la última motivación de las relaciones sexuales por encima de su divisoria genérico-sexual.

La producción tanto de Juan como de Luis Goytisolo está orientada parcialmente también hacia las relaciones erótico-afectivas. Después de su intento de análisis amoroso en Fin de fiesta, Juan Goytisolo explora las posibilidades de otras opciones afectivas, en particular las marginales y habitualmente juzgadas como menospreciables y aberrantes. La inviabilidad de la superación de la frontera física para alcanzar una genuina realización amorosa, que era patente en la obra inicial de Juan Goytisolo, se continúa en su obra posterior. Makbara es una obra que profundiza en la dimensión afectiva pero confirma en última instancia su imposibilidad más allá del gesto utópico. La obra de Goytisolo, en este aspecto afín á contrecoeur a la de Unamuno, elude la sensualidad que queda subsumida a la exploración erótica y sexual que Goytisolo investiga con lucidez y objetividad profundas. En el caso de Unamuno, los sentidos son una diversión para la inteligencia. En el de Goytisolo, la sensualidad es una distracción para la investigación de la sexualidad. La obra de Goytisolo se caracteriza por un deseo de confesión personal sin reservas y la exploración sensual podría percibirse como un alejamiento de ese propósito. Los textos más abiertamente autobiográficos de Goytisolo, Coto vedado y En los reinos de taifa, son los más propicios al análisis personal e insisten de nuevo en la revelación del yo desnudo con aspectos diversos del erotismo por encima de las supuestas veleidades sensuales.

Luis Goytisolo abunda también en esta exploración de la sexualidad sin limitaciones, en su caso no de la sexualidad marginal sino de los grupos sociales acomodados. Se llega 
así a una visión similar a la de Juan Goytisolo. En ambos casos, la sexualidad es término ad quem de la exploración afectiva sin que parezcan posibles las ramificaciones en otras direcciones más que como una sublimación o desviación ilegítimas. Carente de la motivación de la aserción sexual femenina o marginal, el erotismo se convierte en una búsqueda infructuosa de realización personal.

Hay que destacar que el erotismo de la literatura femenina española carece de intención combativa o militante. Presenta nuevas opciones de actuación social que rompen la normativa convencional y, por ello, al no confirmarla, pueden ser leídas como una oposición a esa normativa. Al mismo tiempo, esa oposición ocurre por vía indirecta y el lector debe deducirla o interpretarla a partir de los datos que el texto le ofrece de modo tangencial. La escritura femenina española se ha distanciado de una identificación con una identidad sexual escuetamente definida y no ha querido adherirse a un concepto limitador de la escritura adscrito a una visión separadora de la sexualidad. No obstante, sólo por el hecho de afirmar la diferencia y delimitar algunas de sus articulaciones determinantes la escritura femenina potencia una perspectiva distintiva del mundo. Una perspectiva que no debe ser considerada como excluyente sino como una propuesta de modelos divergentes de posicionamiento social.

La utilización de la sexualidad como un instrumento de sorpresa y shock en el desarrollo narrativo es propia de la ficción adscrita a la cultura popular y de entretenimiento. La novela de misterio o policíaca es especialmente apropiada para esa utilización. La sexualidad abierta e incluso flagrante es un recurso para incrementar el contexto de ruptura moral que es congénito con esta forma ficcional. La novela de Juan Madrid, Regalo de la casa, constituye una ilustración. La figura central, Toni, practica una forma de ética y honestidad personales que no se ajustan a leyes convencionales pero que, por su firmeza y convicción, pueden alcanzar la condición de ejemplaridad. Toni, como Sam Spade en Dashiel Hammett y Carvalho en Manuel Vázquez Montalbán, se caracteriza por su ambivalencia moral y, en realidad, en algunos aspectos, su conducta queda más allá del lado de la ley. Al mismo tiempo, su actitud social e intelectual hace que se proyecte como un paragon de integridad en un medio de corrupción general en el que los principios y sentimientos genuinos han desaparecido por completo. Su forma de integridad personal asegura la firmeza de sus principios personales por encima de los colectivos que carecen de credibilidad. La ostentación de una sexualidad anormal y aberrante entremezclada con la adicción a la droga y la prostitución que subyacen la superficie brillante de la afluencia y el lujo hacen manifiesta la necesidad de la actitud severa de Toni. Es Toni el que desenmascara las coartadas de las personas que investiga y las presenta finalmente en toda su cruda desnudez: "Nelson dormía boca arriba, espatarrado, más gordo y fofo de lo que daba a entender la fotografía que me había dado Draper. Sus pechos eran tan grandes como los de una mujer. Los pliegues de la barriga le caían sobre un pene erecto que sobresalía al menos veinticinco centímetros. El pene estaba cruzado por gruesas venas, nudosas como raíces y fijado a los muslos por tiras de cuero. Era una prótesis de caucho que debía imitar el miembro del abominable hombre de las nieves" (Regalo de la casa, 230).

La hipérbole de la sexualidad, en donde el cuerpo de la pareja comprometida en la criminalidad aparece de forma despiadada, sin ninguna de las coberturas que la posición 
social y económica debería proporcionarles, tiene un propósito doble: hacer manifiesta la naturaleza relacional e inestable de la jerarquía social y producir un sobresalto claramente definido en la conciencia del lector en una narración que abunda en la indeterminación y la ambivalencia. En este caso, la ostentación erótica no deja ningún lugar para la indefinición.

Otra ficción, tanto escrita como filmada, con un destinario amplio y de masas sigue un proceso similar. Antonio Gala es un ejemplo. La pasión turca utiliza un material periodístico en torno a la desventurada historia del amor de una mujer con un extranjero para construir un relato en el que la sexualidad se convierte en un campo fértil para presentar al lector un repertorio amplio de opciones eróticas que rompen con la rutina del amor monógamo. La narración abunda progresivamente en la acumulación de datos y escenas que presentan una sexualidad al desnudo cuyo propósito no es tanto la exploración del hecho sexual como la mediatización del sexo para atraer a un lector medio que puede de ese modo proyectar en el otro la realización de su imaginario insatisfecho.

Mencionaré un pasaje de la novela para ilustrar esta presentación espectacular y gratuita de la sexualidad. La narración en primera persona procede de la mujer implicada en la relación con un extranjero que la explota y abusa violentamente de ella. El pasaje referido presenta un encuentro á trois que repite episodios similares: "Yo, en la refriega, no sabía distinguir de quién era el cuerpo que tocaba, la mucosa en que se hundía mi lengua, el sudor que lamía, la pierna que pasaba sobre mi cuello, el hombro sobre el que descansaba mi cabeza, qué mano retorcía mis pezones o se introducía entre mi carne, qué pie mordía o chupaba o besaba" (La pasión turca, 322). En este fragmento, como en otros paralelos, el texto no explora la naturaleza de las relaciones eróticas de la protagonista con el propósito de desarrollar e investigar su yo sino que convierte la presentación de esas relaciones en un recurso fácilmente efectivo para atraer la atención del lector por motivos sucedáneos que se ajustan a una visión banal y mediatizada de la sexualidad.

La película del mismo título de Vicente Aranda, basada en la novela de Gala, insiste en el mismo grafismo inmotivado, hecho más flagrante en la película a causa de los componentes visuales de los que la narración escrita carece. Los dos textos son ejemplos de la trivialización de que es objeto la sexualidad cuando se presenta aisladamente y queda desconectada de vínculos psicológicos y humanos sin los cuales carece de significación profunda. No son éstos los únicos ejemplos de la reducción sexual del erotismo en la narración española de las dos últimas décadas. Esa orientación es una sobrecompensación por la negación sexual que caracteriza la narración española de la posguerra en la que, como he considerado, la ausencia de referencias sensuales y eróticas es ostentosa, haciendo más abrumadora la elisión de la sexualidad.

Hay otra tendencia en la narrativa actual que se contrapone a la precedente. Dentro de ella, la sexualidad aparece como un vehículo privilegiado de conocimiento de la intimidad personal y del mundo externo. En un conflicto de raigambre psicoanalítica, Eros trasciende a Tanatos y se transforma en un instrumento idóneo para un incremento cognitivo general (Questioning Ethics, 239). El amor conecta así arquetípicamente con la belleza y el saber. La novela de Esther Tusquets sirve como ilustración de esta expansión y enaltecimiento de la sexualidad hacia un territorio que lo convierte en un espacio sin- 
gular. Esa potenciación y expansión no conlleva necesariamente un desenlace feliz de la búsqueda cognitiva. En su experiencia erótica, las figuras de Tusquets avanzan en su conocimiento de sí mismas y su medio. No obstante, ese conocimiento no les conduce a encontrar la dicha afectiva que anhelaban pero les proporciona una conciencia más precisa de sus opciones reales de realización personal. En su caso, Eros les permite una profundización que no hubieran podido alcanzar sin la experiencia afectiva en la que quedaron implicadas. El fin de la relación afectiva es una corroboración de las insuficiencias de la afectividad pero esa corroboración, aun siendo negativa, proporciona una redefinición de la biografía personal que es más completa que la previa a la relación.

Juan José Millás convierte el medio erótico en una investigación de las zonas inexploradas del yo. En El desorden de tu nombre la aventura amorosa extramatrimonial lleva a los protagonistas, Laura y Julio, a percibir su propia conciencia desde perspectivas insólitas que les descubren nuevos aspectos de sí mismos. Esa exploración divergente puede llevarles a una especie de locura pero también les revela áreas incógnitas de sí mismos: "La noción que tenía de sí mismo era la de un voluminoso relieve colocado sobre una fotografía plana que intentaba representar la vida" (El desorden, 140). Impulsado por la creatividad que le permite el amor, Julio se adentra en zonas de su yo que, sin ese impulso inicial, no se hubiera visto capacitado para explorar.

Antonio Muñoz Molina es uno de los novelistas que más ha penetrado en las dimensiones cognitivas y axiológicas del erotismo y la afectividad. En Beltenebros, las relaciones eróticas y afectivas de Darman, un contra-héroe riguroso y absurdo que practica el asesinato ideológico a sangre fría, son el modo como esta figura consigue una redención personal que sin esas relaciones sería inconcebible. De manera paradójica, en el caso de Darman, la elevación por el amor se consigue a través de una prostituta, Rebeca, que sustituye con Darman el icono paternal del que ha carecido con consecuencias funestas para ella. La ficción de Muñoz Molina ha ido evolucionando progresivamente desde la indefinición axiológica de sus primeras novelas (salvo Beatus Ille) a una mayor concreción valorativa que se realiza más plenamente en Ardor guerrero y Plenilunio.

Aunque con connotaciones irónicas y contradictorias, Beltenebros realiza nítidamente ya la orientación axiológica que caracteriza a Muñoz Molina y le convierte en un referente emblemático de la superación de la indeterminación posmoderna (Jameson, 23). Darman llega a ser identificado metafóricamente con la luz que destruye las tinieblas de una corrupción y perversión generalizadas que quedan concretadas en el comisario Ugarte. No obstante, su luz no es propia sino derivada ya que procede de Rebeca, de su bondad e inocencia ingénitas, que se transfieren a él transfigurando los parámetros de su vida. Las novelas de Muñoz Molina suelen producir finales climáticos, dramáticamente intensos, con una fuerza resolutiva notable. Beltenebros estructura esa resolución climática en torno al conflicto luz/tinieblas, una luz platónica que emana idealmente de Rebeca. El triunfo de esa luz sobre Luzbel, la Bella sobre la Bestia, asegura el predominio de una visión moral: "así lo vi Ša UgarteĆ cuando la luz de la linterna estalló como un relámpago contra su cara. Se tapó los ojos con las manos, sin soltar la pistola, pero la luz seguía fija en él y se tambaleaba y hacía gestos extraños moviendo la cabeza, como si huyera de un hierro candente que ya estaba quemándolo. Arriba, en las últimas gradas, más alta que 
nosotros, la muchacha, pálida y desnuda, mantenía inmóvil la linterna y su círculo de incandescencia trazaba una fría y blanca línea de luz que iba a romperse en la cara de Valdivia" (Beltenebros 236, cursiva mía).

La sobredeterminación axiólogica pretende fijar el significado de la textualidad para disolver las ambivalencias que previamente han caracterizado la narración. Ugarte sufre la retribución consecuente por su trayectoria de persecución y tortura de los miembros de la oposición clandestina. Quien le vence finalmente es la luz metafórica de Rebeca que, en su desnudez y desamparo, materializa la necesidad de despojarse de las falsas protecciones ideológicas para prevalecer sobre Ugarte. Es una prostituta la que derrota al poderoso inspector que la oposición no había podido desenmascarar. La ambigüedad se resuelve de manera inequívoca. A través de la exploración erótica Darman alcanza una legitimidad moral que él pretende hallar para disipar su propia culpabilidad. Ese propósito no ha podido lograrlo hasta su encuentro con Rebeca. Eros deriva así en este caso hacia la definición axiológica.

Pilar Miró, en la versión cinematográfica de la novela, incrementa y potencia esa determinación y la convierte de moral en claramente política e ideológica. En la película, la figura de Darman pierde progresivamente la ambigüedad que tiene en la narración escrita y adquiere dimensiones heroicas. Esas dimensiones se corroboran en su enfrentamiento final con Ugarte que concluye en la muerte degradadamente grotesca del inspector. Con la muerte de Ugarte se condena por extensión la historia sombría del franquismo. A partir de la relación impersonal y fría de Darman con Rebeca (ejemplificada en el encuentro y transacción entre los dos en la habitación del hotel), Darman evoluciona hacia la reconfiguración de sí mismo: de asesino por encargo se convierte en un brazo ejecutor de la justica colectiva.

La novela joven reciente insiste en la desmitificación de las relaciones eróticas que han perdido el aura reivindicativa que tuvieron en el pasado. La sexualidad deja de percibirse como un instrumento liberador o de combate para presentarse como un hecho cotidiano y trivial que ha perdido gran parte de sus atributos cognitivos y éticos. Historias del Kronen, de Angel Mañas, o Héroes, de Ray Loriga, son ejemplos de esta devaluación del erotismo en favor de otras experiencias percibidas como más sugestivas. En las dos novelas mencionadas, la sexualidad aparece subordinada a la música de rock, las drogas y otras experiencias más inmediatamente gratificantes. Esta reorientación se halla también en el cine joven, desde Tesis de Amenábar a los road movies (Antártida, África) en los que lo erótico aparece como una adición al movimiento incesante sin que llegue a desarrollarse en una exploración humana ulterior.

\section{Conclusión. El positivismo de los sentidos}

La ficción de las últimas dos décadas produce una transformación radical en su visión del cuerpo con relación a la prolongada trayectoria cultural española de minusvaloración de lo corporal y con frecuencia de su negación y supresión, que ha sido predominante desde la mística a Unamuno. Hemos pasado de la elisión del cuerpo y el deseo a la potenciación del impulso corporal como la única realidad. Este cambio se opera a partir de la negación ontológica e ideológica que la condición actual ha propuesto como 
su característica más definitoria. Todo sistema metafísico o ideológico se juzga como una falacia que debe evitarse. La afirmación del cuerpo es una manera de compensar la supresión de todo impulso transcendente. La supresión de las estructuras supraindividuales se sustituye con la concreción positiva de los sentidos, la seguridad incontrovertible de lo físico y el deseo. El que la novela (y su afiliado narrativo, el cine) adopten esta nueva situación epistémica como propia es consistente con su naturaleza: la ficción narrativa se realiza con datos y figuras concretas en las que lo tangible y sensorialmente verificable tienen una significación primordial e incontestable.

\section{Bibliografía}

Etxebarría, Lucía, Beatriz y los cuerpos celestes. Destino, Barcelona, 1998.

Foucault, Michel, Histoire de la sexualité, I. Gallimard, París, 1976.

Gala, Antonio, La pasión turca. Planeta, Barcelona, 1993.

Gibson, Andrew, Towards a Postmodern Theory of Narrative. Edinburgh UP, Edimburgo, 1996.

Goytisolo, Juan, Coto vedado. Seix Barral, Barcelona, 1985.

-. Makbara. Seix Barral, Barcelona, 1980.

-. En los reinos de taifa. Seix Barral, Barcelona, 1986.

-. Fin de fiesta. Círculo de lectores, Barcelona, 1962.

Grandes, Almudena, Las edades de Lulú. Tusquets, Barcelona, 1989.

Higginbotham, Virginia, Spanish Film Under Franco. Texas UP, Austin, 1988.

Jameson, Fredric, The Cultural Turn. Verso, Londres, 1998.

Kearney, Richard y Mark Dooley, Questioning Ethics. Routledge, Londres, 1999.

Kellner, Douglas, Critical Theory, Marxism, and Modernity. The Johns Hopkins UP, Baltimore, 1992.

Kolocotroni, Vassiliki, et al. eds., Modernism. Chicago UP, Chicago, 1998.

Loriga, Ray, Héroes. Plaza \& Janés, Barcelona, 1993.

Madrid, Juan, Regalo de la casa. Alfaguara, Madrid, 1986.

Mañas, Angel, Historias del Kronen. Destino, Barcelona, 1994.

Millás Juan José, El desorden de tu nombre. Alfaguara, Madrid, 1988.

Muñoz Molina. Antonio, Ardor guerrero. Alfaguara, Madrid, 1995.

-. Beltenebros. Seix Barral, Barcelona, 1989.

-. Plenilunio. Alfaguara, Madrid, 1997.

Tusquets, Esther, El mismo mar de todos los veranos. Lumen, Barcelona, 1978.

-. Para no volver. Lumen, Barcelona, 1985.

\section{FIKCIJA IN EROTIČNOST. VRNITEV TELESA V SODOBNO ŠPANSKO PRIPOVEDNIŠTVO}

Avtor opozarja na radikalno preobrazbo pojmovanja erotičnosti v španskem pripovedništvu v zadnjih dveh desetletjih, saj je telesnost $v$ španski književnosti od mistikov do Unamuna pogosto zanikana oz. povsem odsotna. Takšna sprememba je vidna v sodobni kulturi od ontološke in ideološke negacije dalje, pojavlja pa se predvsem v romanu in filmu. Danes se pripovedna fikcija naslanja predvsem na podatke in konkretne like, zato je bistvenega pomena vse, kar je oprijemljivo in kar je s čuti mogoče preveriti. 